\title{
Tsafon
}

Revue d'études juives du Nord

73 | 2017

Connaissance de la Shoah : témoignages, enseignements, visites

\section{Á nos lecteurs}

Tsafon

\section{(2) OpenEdition}

\section{Journals}

Édition électronique

URL : https://journals.openedition.org/tsafon/315

DOI : $10.4000 /$ tsafon.315

ISSN : 2609-6420

Éditeur

Association Jean-Marie Delmaire

Édition imprimée

Date de publication : 1 juin 2017

Pagination : 5-6

ISSN : 1149-6630

\section{Référence électronique}

Tsafon, «Á nos lecteurs », Tsafon [En ligne], 73 | 2017, mis en ligne le 31 mai 2018, consulté le 24 juin 2021. URL : http://journals.openedition.org/tsafon/315 ; DOI : https://doi.org/10.4000/tsafon.315 


\section{À NOS LECTEURS}

Le dossier de ce numéro de Tsafon se présente différemment des dossiers des numéros précédents. En effet, sur le thème de la "Connaissance de la Shoah», il donne à lire trois volets: deux témoignages d'anciens déportés, sept expériences d'enseignement et deux comptes rendus d'activités dispensées dans des lieux de mémoire.

Les deux témoins sont Haïm Vidal Sephiha et Charles Baron. Le premier raconte sa «marche de la mort» entamée quelques jours avant l'ouverture du camp d'Auschwitz par les Soviétiques. Ce qui fait dire au témoin que, pour lui et ses nombreux compagnons d'infortune, la prétendue libération fut en fait le début d'une mise à mort dont peu échappèrent. Le second évoque ses difficiles pérégrinations d'un camp à l'autre mais durant lesquelles « un sacré pot» lui permit de survivre.

Les six enseignants français sollicités ont répondu différemment. Trois ont préféré élaborer un compte rendu de leurs expériences: enseignement, voyages, écoute de témoins etc. Trois autres ont accepté que Danielle Delmaire, responsable du dossier, vienne dialoguer avec leurs élèves. L'accueil et l'échange furent toujours très positifs. Une septième enseignante rapporte ce qui se fait en Allemagne.

Enfin les responsables de programmes pédagogiques de deux instituts gardiens de la mémoire de la Shoah ont également accepté de donner des informations sur leurs activités. Il s'agit, d'une part, du Mémorial de la Shoah à Paris, le rapport de M. Orjekh est suivi des impressions d'un enseignant qui bénéficia de services du Mémorial, et, d'autre part, de Kazerne Dossin ou «le musée et centre de documentation sur l'Holocauste et les droits de l'Homme de Malines » en Belgique.

Le dossier est présenté par Danielle Delmaire qui en fait une synthèse bien étoffée. 
Une seule contribution nourrit la partie Varia. Il s'agit de l'étude d'Elżbieta Wichrowska sur deux femmes juives de Varsovie à la charnière des $\mathrm{XVIII}^{\mathrm{e}}$ et $\mathrm{XIX}^{\mathrm{e}}$ siècles : Judyta Jakubowicz et Tamerle Sonnenberg-Bereksohn. Il faut remercier l'auteure d'avoir sorti de l'oubli deux femmes qui évoluèrent dans le monde des affaires et des cercles littéraires, monde dominé par les hommes. Elles suppléèrent leurs maris, voire les remplacèrent. Elles furent l'une la propagatrice de la Haskala en Pologne et l'autre le soutien solide du hassidisme. L'article original a été écrit en polonais et il est traduit par Monika Salmon-Siama.

Dans la dernière rubrique «Édition », Olivier Rota reproduit et traduit de l'anglais une lettre du révérend William W. Simpson, secrétaire du Council of Christians and Jews anglais, adressée à Edmond Fleg, en 1955. Cette correspondance donne un aperçu éclairant sur l'aura dont bénéficia Fleg en Angleterre, après la guerre, dans les milieux chrétiens ouverts au rapprochement avec les représentants du judaïsme.

Comme dans le précédent numéro nous ajoutons une rubrique d'hommages. D'abord, un hommage à Év. Palagean par Francis Schmidt en reconnaissance des avancées accomplies dans l'histoire des juifs au Moyen Âge par cette éminente chercheuse. Puis deux hommages à deux grands historiens, malheureusement décédés récemment: Henri Minczeles (1926-2017), historien, journaliste, militant, conférencier, animateur radio, dirigeant communautaire par Michèle Tauber, et Joseph Mélèze-Modrzejewski, historien de l'hellénisme, par Christophe Batsch.

Comme habituellement, des recensions d'ouvrages et des informations complètent ce numéro.

À toutes et à tous, bonne lecture 